\title{
International Space Station United States Orbital Segment Oxygen Generation System On-orbit Operational Experience
}

\author{
Robert J. Erickson \\ NASA, Marshall Space Flight Center \\ John Howe Jr \& Galen W. Kulp \\ Hamilton Sundstrand, Windsor Locks CT \\ Steven P. Van Keuren \\ MEI Technologies, Inc.
}

\begin{abstract}
The International Space Station (ISS) United States Orbital Segment (USOS) Oxygen Generation System (OGS) was originally intended to be installed in ISS Node 3. The OGS rack delivery was accelerated, and it was launched to ISS in July of 2006 and installed in the US Laboratory Module. Various modification kits were installed to provide its interfaces, and the OGS was first activated in July of 2007 for 15 hours. In October of 2007 it was again activated for 76 hours with varied production rates and day/night cycling. Operational time in each instance was limited by the quantity of feedwater in a Payload Water Reservoir (PWR) bag. Feedwater will be provided by PWR bag until the USOS Water Recovery System (WRS) is delivered to ISS in fall of 2008. This paper will discuss operating experience and characteristics of the OGS, as well as operational issues and their resolution.
\end{abstract}

\section{INTRODUCTION}

The U.S. regenerative Environmental Control and Life Support Systems (ECLSS) have been developed to enable the ISS to expand its crew size from three to six crewmembers. These regenerative systems include the Water Recovery System (WRS) and the OGS. The OGS includes the Oxygen Generation Assembly (OGA), the Power Supply Module (PSM) that supports the OGA, and scars to accommodate the later addition of a Sabatier Carbon Dioxide Reduction Assembly (CRA). Earlier development activities are summarized in references 1-7. shown in Figure 2. Feed water from the potable water bus enters the assembly through the Water Orbital Replacement Unit (ORU) and flows through an Inlet Deionizing Bed, which serves as an iodine remover as well as a coalescer for any gas bubbles that may be present in the feed water. If gas bubbles are detected by the gas sensor downstream of the DI bed, the feed water is rejected to the waste water bus. This serves to prevent any oxygen that may be present in the feed water from mixing with generated hydrogen. Water is electrolyzed into oxygen and hydrogen in the Hydrogen ORU, which contains the electrolysis cell stack. Oxygen produced by the cell stack passes through the Oxygen Outlet ORU containing a water absorber, which protects the downstream hydrogen sensors from liquid moisture. The Hydrogen Sensor ORU monitors the product oxygen for the presence of hydrogen, which would indicate a problem with the cell stack and signal the controller to shut down the OGA. The Rotary Separator Accumulator (RSA) within the $\mathrm{H}_{2}$ ORU separates the product gaseous hydrogen from the water which is re-circulated by the Pump ORU. The Nitrogen Purge ORU serves to purge system lines upon shutdown with nitrogen, and the Process Controller ORU is responsible for OGA System command/control and communication with the ISS Multiplexer/Demultiplexer (MDM).

\section{OXYGEN GENERATION SYSTEM}




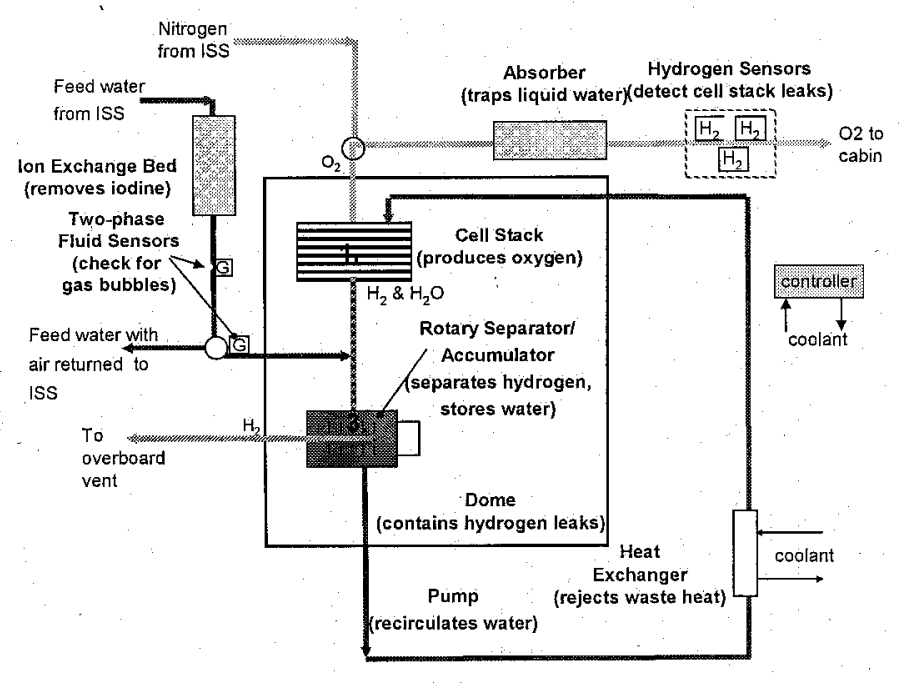

Figure 1. OGA Simplified Schematic

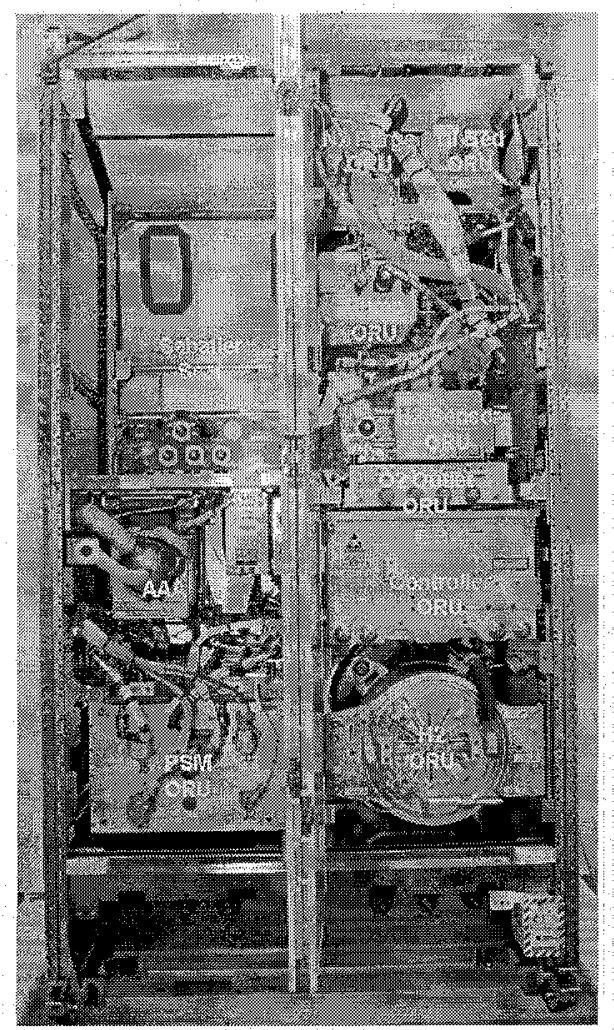

Figure 2. Oxygen Generation System

The OGA is designed to generate oxygen at a maximum nominal rate of $5.4 \mathrm{~kg} /$ day $(12 \mathrm{lb} /$ day $)$ when operated on day/night orbital cycles, and also at a selectable rate between 2.3 and $9.2 \mathrm{~kg} /$ day (5.1 and $20.4 \mathrm{lb} /$ day) when operated continuously. At the nominal rate, the OGA can support oxygen needs for 4 crew, biological specimens, and atmosphere leakage, while at the maximum rate it can support 7 crew, biological specimens, and atmosphere leakage. The assembly consumes $3573 \mathrm{~W}$ when processing, and $382 \mathrm{~W}$ during standby. The product oxygen meets quality specifications for temperature, free water, dewpoint, and hydrogen content.
POWER SUPPLY MODULE OVERVIEW - The PSM is shown in the lower left of the OGS rack in Figure 2. The PSM provides 10-55 amps current to the OGA cell stack during Process mode and $1.0+/-0.2$ amps during Standby mode, with a minimum efficiency of $91 \%$ in Process mode. The PSM is designed for 60,000 process/standby cycles, and a 10-year life.

\section{ON-ORBIT OPERATION}

The OGS has been activated three times since its installation in the ISS. In the first activation, the OGS operated in Standby ( $2 \%$ of maximum oxygen production) for 6.8 hours and in Process (25\% to $100 \%$ of maximum oxygen production) for 15.8 hours, which converts to approximately 13.4 Equivalent Full Power Hours (EFPH). During the second activation, the OGS operated in Standby for 26.5 hours and in Process for 47.1 hours, which convert to approximately $31 \mathrm{EFPH}$. The third activation production parameters have not yet been quantified, but the OGS operated between 25\% and $100 \%$ production rates, in both cyclic and continuous modes, for approximately 112 hours. The following sections describe the activations in more detail.

FIRST ACTIVATION, ON-ORBIT DAY 2007:192. (JULY 11) - When the first activation of the Oxygen Generation System (OGS) was attempted on July 11, 2007, it was understood that there could be some problems with startup. The system had been dormant-apart from powering the controller, the recirculation pump, and some valves-since December 2005. It was known that the water in the hydrogen side of the cell stack would permeate to the oxygen side, and the nitrogen in the oxygen side would permeate to the hydrogen side. As a result, the RSA would be low in water and would likely cause a shutdown. Also, since water permeates to the oxygen side of the stack, this water would then be pushed into the hydrogen dome during the initial nitrogen purge of the cell stack, which would extend the needed time to dry out the dome.

In light of this information, it is not surprising that there were 11 fast shutdowns caused by system conditions during the attempted startup of the OGS. Fault limit overrides were implemented to overcome many of the difficulties of starting the system. The timeline for the first activation is shown in Figure 3.

Before the OGS can start, the hydrogen dome must be evacuated and dried of any water. The dome must be dry to allow for leakage detection, and enough time must be given to evacuate the dome to vacuum to evaporate any resident water so that the dome pressure will not rise above the pressure trip-point after the evacuation procedure is complete. Not enough time was allowed for this evacuation procedure in the software, so high hydrogen dome pressure caused the first two fast shutdowns. As mentioned above, these shutdowns were caused by the fact that the system was dormant for so long that water accumulated in the oxygen side of the cell stack, which was then purged into the hydrogen 
dome. The first startup attempts dried the dome enough so that, by the third attempt, the dome had dried enough so another high dome pressure failure was avoided.
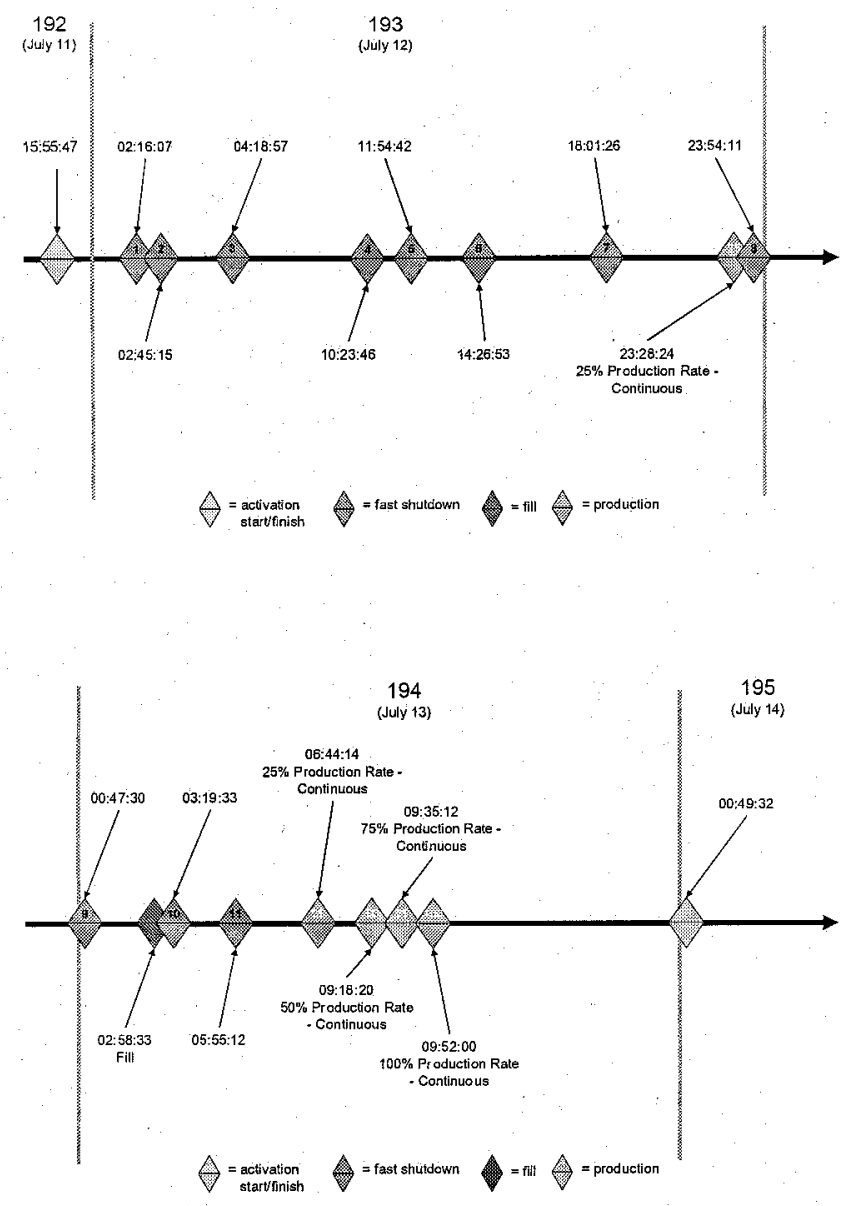

Figure 3: $1^{\text {st }}$ Activation Timeline

A low RSA volume caused the third fast shutdown. This was expected to be a problem due to water crossover in the cell stack, so overrides were prepared for the RSA trip point and speed so that the system could continue with the startup procedure and eventually fill the RSA with water.

High water flow rate in the OGS water recirculation loop appeared to be the cause of the fourth and fifth shutdowns. However, it is speculated that it was not, in fact a high flow rate that caused the shutdown, but an anomaly with the Venturi used to measure the flow rate. Since the RSA speed was increased after the third shutdown to remedy the low RSA water condition, it was speculated that the extra speed in the RSA caused an increase in water flow. However, a similar condition was observed in ground testing, and was attributed to gas bubbles in the Venturi pressure taps causing errors in the readings. The solution implemented in the ground tests was to push high flows of water through the Venturi to purge the bubbles. This solution worked, and so the bubble theory was accepted. In order to continue beyond this failure, the shutdown trip-point was overridden to a higher flow rate. Higher recirculation flow rates were used during on-ground system testing, and there is no safety limit restricting the upper limit of the recirculation flow, so this override was not considered a problem. Later in the startup procedure, it was found that this initial high reading from the Venturi decreased back to expected levels.

After the fifth shutdown, Standby mode was achieved with RSA quantity nominal at over $328 \mathrm{ml}$. After commanded Shutdown, the overrides for the RSA were removed. The community may have thought that a water fill had been initiated during the startup, making these overrides unnecessary. However, the next startup attempt, number six, showed that the RSA was still too low and caused the sixth shutdown as a result. The low RSA quantity overrides were reinstated for the next startup attempt.

Even though the RSA water level software limits had been overridden low for the seventh startup, hardware shutdown limits exist that measured the water level readings and prevented the recirculation pump from starting. Software fault limits exist for the delta pressure over the pump, and the pump speed, which tripped the seventh shutdown. Previous startups had avoided this fault by increasing the RSA speed, which increased the delta pressure reading in the RSA. The higher pressure met the hardware limit requirements. Once the RSA speed was no longer overridden high, the delta pressure reading in the RSA was no longer high enough for the hardware shutdown limits. The higher RSA speed override was implemented for the next startup attempt.

The eighth startup attempt was not only able to reach Standby operation, where a small amount of power is supplied to the cell stack, but was also able to reach an oxygen production rate of $25 \%$. However, when an attempt was made to remove the RSA speed override while the system was running, the system shut down due to the change in system operation caused by the removed override. For the next activation attempt, the speed override was not added to the override list.

Since operation of the cell stack was reached in the eighth startup, more water was consumed by the system, and hydrogen gas was now in the hydrogen side of the cell stack. Also, the system did not initiate a water fill, because at low production rates, less water is required by software to be in the RSA. As a result, at the ninth startup, the low RSA level was lowered even more when the recirculation pump started and pushed hydrogen gas from the cell stack into the RSA. This caused another fast shutdown, requiring the previously removed RSA overrides - the speed and quantity overrides-to be reinstated for the next startup attempt.

After the tenth startup, the system finally initiated a water fill. However, there was still a speed override on the RSA, which forced the RSA to run at a specific rotational speed. Because there was a water fill, there was more 
torque required to maintain that speed. Unfortunately, the RSA motor current reached a hardware limit and prevented the RSA from reaching the required speed, which was noticed by software (a tolerance fault) and caused the tenth shutdown. An attempt was made to start the system again without change, but the same shutdown occurred.

Activation was finally successful with a complex set of overrides and a process to gradually remove these overrides after activation was achieved. After the 11 shutdowns, the system ran well and was able to run at $25 \%, 50 \%, 75 \%$, and $100 \%$ production. Once the system reached $100 \%$, it was run at that level for several hours until the water supply was exhausted.

SECOND ACTIVATION, ON-ORBIT DAY 2007:275 (OCTOBER 4) - Much was learned during the first activation of the OGS which was applied to the second activation. The activation procedure was modified to include several fault limit overrides that were implemented during the first activation. A longer period of time was allowed to evacuate the dome so that any water in the dome would have plenty of time to evaporate. The maximum recirculation loop flow rate trip point was increased. The low RSA water level limits were decreased and the RSA speed command was kept within its capability. As a result, the system was brought up to power on the first startup attempt and was able to complete a full day of $50 \%$ day/night cycling. The timeline for the second activation is shown in Figure 4.

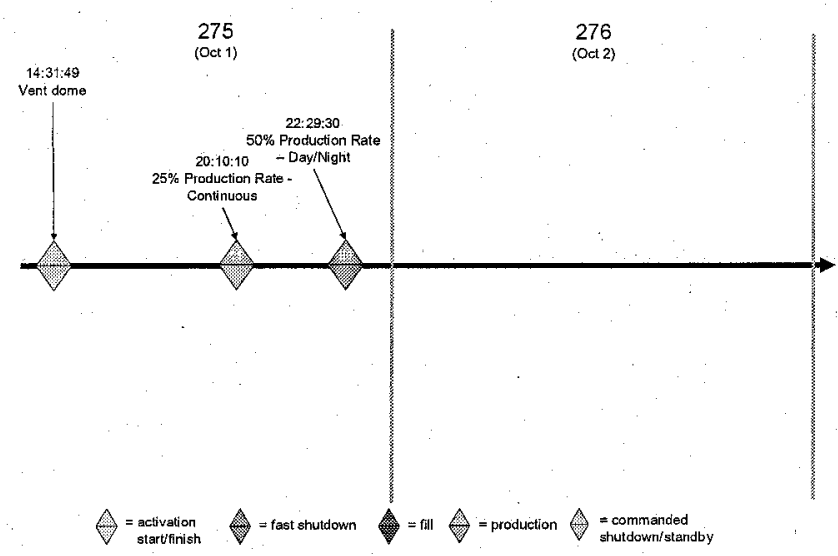

(Keep this picture together with the one on the following column so that it doesn't look like there's a figure title missing)

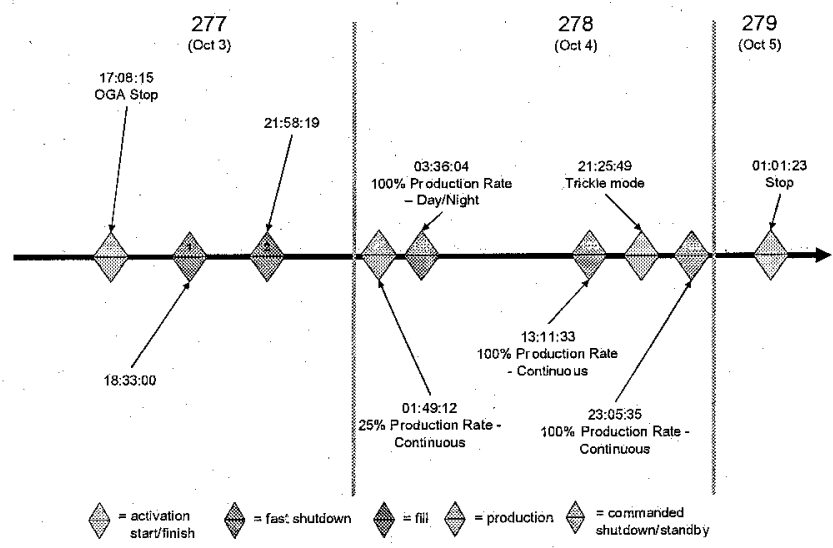

Figure 4: $2^{\text {nd }}$ Activation Timeline

To simulate a loss of power, Stop was commanded to immediately remove power from all effectors while at $50 \%$ production rate. When a restart was attempted, an RSA high level shutdown was tripped when the system was commanded to Standby operation. This occurred because when the system powers the cell stack, hydrogen production pushes a fair amount of water into the RSA. In previous startups, this failure was close to being tripped, but never caused a shutdown. A second attempt to start the system was made with no changes, but the same failure occurred. Therefore, the maximum RSA water level limit was temporarily increased in the software to accommodate this condition.

The system was started again with no problems, and proceeded to $25 \%$ production for about 2 hours. Next the system was set at day/night cycling at $100 \%$ production for about 10 hours to demonstrate it's functionality at that power level. It was then switched to $100 \%$ continuous production for another 8 hours.

Next, the system was commanded to standby since a long Loss Of Signal (LOS) period was imminent, and it was known that the system had nearly exhausted its external water supply. It is desirable to shut the system down manually before the external water supply is completely exhausted to prevent the RSA water level from being low for the next startup. After about 2 hours of standby operation, the LOS passed and the system was powered to $100 \%$ continuous production with no problems. This power level was maintained until the system consumed all of its available water.

THIRD ACTIVATION, ON-ORBIT DAY 2008:058 (FEBRUARY 27) - At this time there was a comprehensive set of overrides in a procedure, including two additional RSA high-quantity overrides identified in Activation \#2. We had, however, reduced the RSA override commanded speed due to its inability to reach the speed commanded. Added to this was the potential increased loss of RSA quantity due to cell stack diffusion into the evacuated dome for 144 days since Activation \#2. See the timeline for faults in Figure 5: 


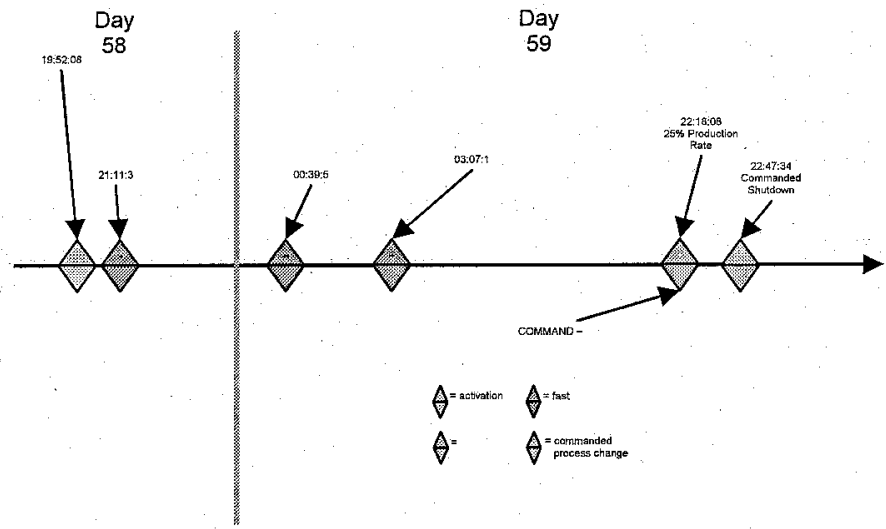

Figure 5: $3^{\text {rd }}$ Activation Timeline

After fault \#1 and \#2, before which the RSA interlock with the pump did not set, the RSA speed was increased to the level which had previously provided a successful startup. This allowed the startup to progress further, but also resulted in fault \#3 as the RSA differential pressure slowly decreased. A successful startup was enabled by a complex set of overrides with the goal of providing cell stack current and an RSA fill as soon in the startup process as possible. This was done by disabling as many built-in tests as possible and commanding Process at $25 \%$ rate instead of Standby. After an RSA fill, Shutdown was commanded to re-enable built-in tests. Standby was commanded with the procedural overrides as officially documented.

\section{GENERAL DISCUSSION OF STARTUP FAILURES}

The faults encountered during startup attempts are of five classifications.

\section{High dome pressure}

2. Pump speed-The recirculation pump is not running when it should.

3. High recirculation flow differential pressureBubbles in the recirculation loop are blocking the flow sensor.

4. High or low RSA quantities

5. Tolerance faults

HIGH HYDROGEN ORU DOME PRESSURE - The first two faults in Activation \#1 were because the dome pressure did not reduce to below shutdown limits after a startup nitrogen purge. This was considered to be because of liquid that still existed in the dome. The problem did not occur after, but a permanent override extending the dome venting after a startup purge was implemented, since there was determined to be no impact to Safety.
RSA DIFFERENTIAL PRESSURE INTERLOCK WITH THE RECIRCULATION PUMP - If the differential pressure across the RSA at sensor 7331-3 cannot exceed $64.65 \mathrm{mmHg}$ (reset limit) or drops below 56.89 $\mathrm{mmHg}$, a hardware interlock prevents the recirculation pump from being powered. This is to prevent gas from entering the recirculation loop and being a source of combustion. Figure 6 shows a startup sequence from Activation 1, which did not reset the interlock (pump never turned). The initial part of the chart shows RSA operation at a lower speed to evolve dissolved gas.

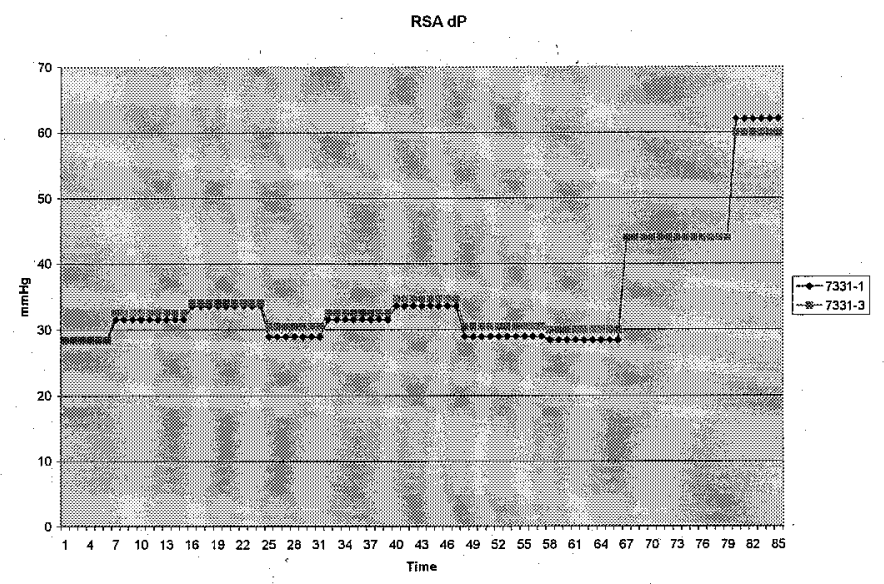

Figure 6: RSA Differential Pressure Sensors, 2007 Day 193, GMT 4:17

\section{RSA dP}

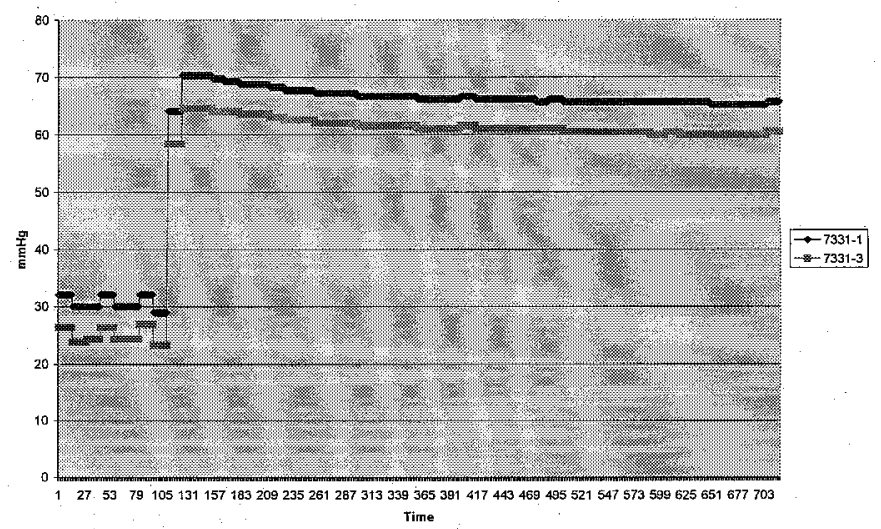

Figure 7: RSA Differential Pressure Sensors, 2008 Day 059, GMT 2:58

It's evident that the pressure reading of the two RSA differential pressure sensors 7331-1 (software only, and the quantity control sensor) and $7331-3$ (hardware interlock) are not consistent. On occasion as shown in Figure $7,7331-3$ is as much as $5 \mathrm{mmHg}$ below 7331-1. The pump interlock function of 7331-3 cannot be inhibited or modified. The 7331-3 interlock does not result in a software fault by itself, but related software faults will result if the pump does not come up to speed within 15 (default) seconds. The first three activations have been achieved by overriding the RSA speed from default of 1500 RPM to 1783 RPM. This increases the 
differential pressure by centrifugal force toward the outside of the RSA. The value is reduced after successful activation to reduce wear on the RSA.

For activation \#3, it was also necessary to accelerate cell current and RSA fill by inhibiting built-in tests. Figure 7 illustrates how this assists in successful activation before the 7331-3 interlock can be tripped.

HIGH RECIRCULATION FLOW DIFFERENTIAL PRESSURE FAULT - Activation \#1 Faults 4 and 5 were due to high differential pressure across the flow sensor venturi FL_7531_1. Previous to these faults, the RSA quantity reading had dipped to $98 \mathrm{ml}$. Since this value is filtered, the actual value may have been lower. This is evidence that gas actually did enter the recirculation loop during our attempt to restart with low RSA quantity. The gas cleared itself after a subsequent attempt (fault 5).

HIGH OR LOW RSA QUANTITIES - There are problems with the reference values of the RSA leakage detection. These faults protect against leakage into the recirculation loop from process coolant, or leakage out of the recirculation loop into the rack. The minimum reference value for the low level fault is $327.74 \mathrm{ml}$. If the measured RSA quantity is more than $98.3 \mathrm{ml}$ below this value, a low quantity fault will occur. Another reference value for the high fault is set at the lowest actual RSA quantity, and the fault will occur if the quantity increases by $163.9 \mathrm{ml}$ when the system is not in a fill mode. If the lowest value is $200 \mathrm{ml}$, the fault will occur at $363.9 \mathrm{ml}$. The limits must be expanded for successful activation, and then reset to perform their safety function during OGS operation.

TOLERANCE FAULTS - During Activation \#1, the RSA speed was overridden to a faster speed than it was able to support. This resulted in a tolerance fault between the RSA commanded and actual speed. The default limit is 54 RPM. Another tolerance fault was encountered when the speed was reduced and the software did not anticipate a delay to reach the commanded speed. The tolerance is increased to 200 RPM, and returned to default after successful activation.

FAULT SUMMARY - The RSA 7331-3 interlock can be "fooled" into allowing startup by increasing the RSA rotational speed. This is at the risk of allowing gas into the recirculation loop if the level is too low. The remaining software faults can be avoided by up to about 15 overrides which must be removed after successful activation.

Some of the overrides identified as necessary for successful activation were made "permanent". These had no impact on operation or safety function, and included recirculation loop flowrate high limit and transient time for the dome to be evacuated after a startup nitrogen purge of the cell stack.

Other overrides reduced the hazard controls for leakage detection temporarily until successful activation. The controls were then re-enabled by resetting the overrides after a successful startup was achieved.

\section{PLANS FOR FUTURE SUCCESSFUL ACTIVATIONS}

Only one potential issue with the OGS operation while in Process or Standby has been identified. During an extended period in Standby, the heated hydrogen outlet tubing increases in temperature due to reduced product hydrogen cooling flow. The temperature sensor is downstream of the hydrogen outlet heater, and they are both between the RSA and a regulator which maintains pressure against space vacuum. As soon as hydrogen flow commences the temperature spikes. The highest temperature seen was $4.3 \mathrm{C}$ below the default shutdown limit, which is based on the derated material limits. This value will be monitored, but currently no changes are planned.

After the end of each OGS Activation, the RSA quantity has been maximized on commanded Shutdown. Since the WDS pressure drops as its accumulator quantity decreases, the RSA fill quantity also decreases. At some point, the RSA quantity increase will be insufficient for a successful fill. At this point, software will attempt a second fill in 30 seconds. Therefore, Shutdown is commanded after a confirmed RSA double fill.

Since the OGS dome is evacuated during extended shutdowns, measurable diffusion occurs from the OGS cell stack to space. The time between activations 2 and 3 was 144 days. Activations will be scheduled within approximately 90 days of the previous to minimize water loss.

The overrides for successful activation will be as baselined in the Activation \#3 procedure, with the RSA rotational speed increased to 1783 RPM. This speed contributed to success in Activations 1 and 3 , and the procedure, including all overrides, was successfully used

In the future, the RSA quantity may not be maximized when preparing for extended storage. This may be due to OGS failures, interface failures, or resource issues. It may therefore be necessary to fill the RSA from feedwater sources at the next operation opportunity using overrides. An overfill may occur during this process. There are safety and operational concerns with this process that still need to be addressed. The reason that the OGS software does not allow an RSA fill until activation is complete is so that the gaseous composition within the RSA can be first confirmed to be pure hydrogen by hydrogen production and venting. RSA fill quantity is limited by design and software so that dissolved oxygen in the feedwater cannot create a combustible mixture within the RSA when evolved. Investigation into a method of recovering proper RSA quantity will continue.

\section{HYDROGEN SENSOR ORU PURGE ADAPTER (HOPA)}


When in operation, the OGS produces oxygen with a high relative humidity. Heaters in the outlet stream and in the Hydrogen Sensor ORU prevent condensation from forming. When the OGS is powered down, the heaters are shut off, gas flow is restricted, and there is a high potential for condensation to form on the cooling sensor dies inside the Hydrogen Sensor ORU. Sensor dies could be damaged if power is applied when water has collected on the dies. The Hydrogen Sensor ORU Purge Adaptor (HOPA) was designed and manufactured to purge moist oxygen from the Hydrogen Sensor ORU after OGS power-down. This purge prevents condensation from forming on the sensor dies and preserves sensor calibration life. The HOPA is made up of three tools: Evacuation, Inlet and Outlet Tools. Reference Figures 8-10.

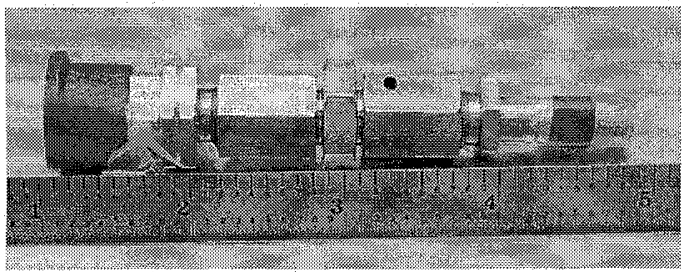

Figure 8: Evacuation Tool

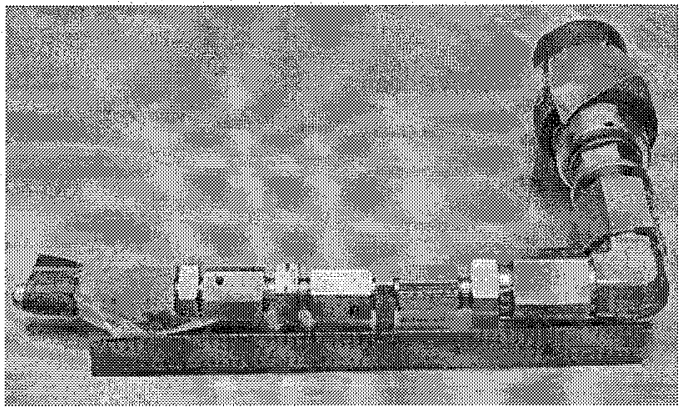

Figure 9: Inlet Tool

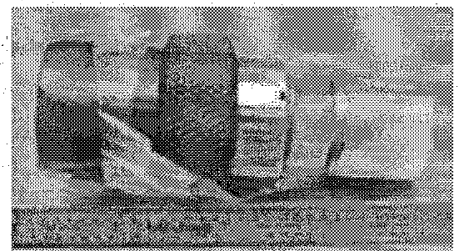

Figure 10: Outlet Tool

HOPA PROCEDURE - The process to purge the Hydrogen Sensor ORU is quite simple. After OGS shutdown, the crew disconnects inlet and outlet quick disconnects from the Hydrogen Sensor in the OGS. Then the crew connects the HOPA Outlet and Inlet tools to the respective outlet and inlet quick disconnects on Hydrogen Sensor ORU. Reference Figure 11. The HOPA Evacuation Tool is connected to the Portable Oxygen Apparatus (PBA) Extension Hose which provides a source of dry oxygen. The crew "evacuates" potential contaminants from the PBA lines for five minutes. Then they disconnect the evacuation tool, reconnect the PBA line to the inlet tool, and purge the Hydrogen sensor to remove any humidity. The HOPA was successfully used by space station crew in October 2007 and March 2008 after the OGS activations.

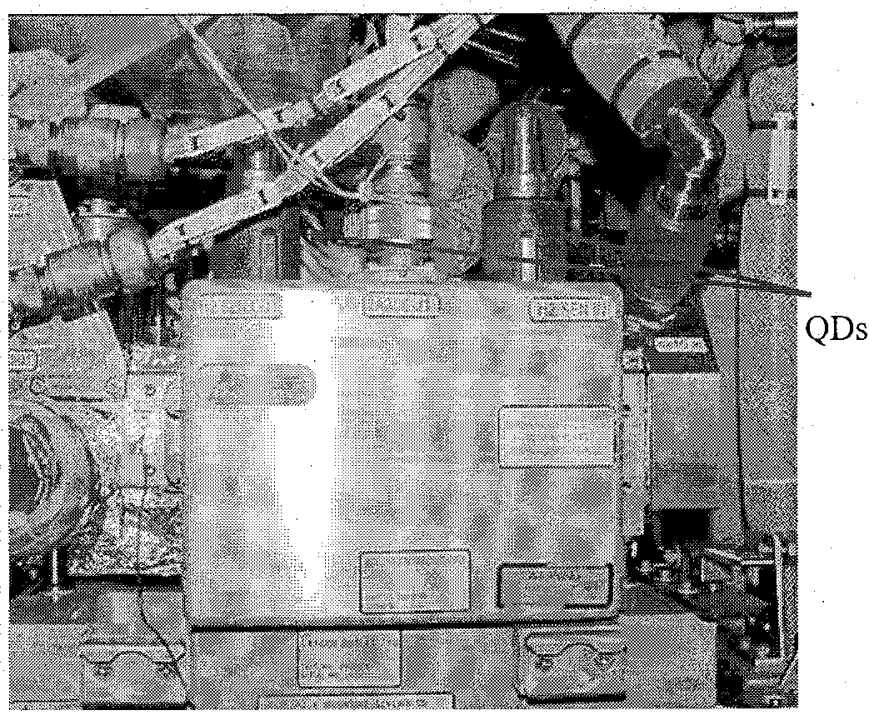

Figure 11: Hydrogen Sensor installed in OGS

HOPA IMPACT ON CALIBRATED LIFE - Currently, the OGS is operated approximately every 90 days for about a one-week period. Continuous operation is not possible because the Water Recovery System (WRS) is not onorbit to supply a continuous source of potable water. The OGS is only operated when potable water is brought to the space station via the Shuttle. It is desirable to power down the OGS when it is not producing oxygen so that valuable power is not consumed, cooling systems are not taxed, and component life is not wasted on items such as on the 150 day calibration life of the Hydrogen Sensor ORU. The calibration life of the Hydrogen Sensor ORU is determined by total power on-time, so as long as the Hydrogen Sensor ORU is powered, its calibration life is being used whether or not the OGS is producing oxygen. Once the WRS is operational on orbit the OGS may continuously operate unless maintenance is required. If shutdown is longer than a predetermined time, the HOPA will need to be used to purge humidity from the Hydrogen Sensor.

As mentioned before, the OGS produces oxygen with high relative humidity and without the heaters warming the Hydrogen sensors, condensation would form on the sensor die. Tests have shown the potential for damage to energized Hydrogen Sensors. If water is on the sensor's die, electrolysis may result in physical damage or may cause the devices to indicate an incorrect level of Hydrogen. Without the HOPA, the Hydrogen Sensor could not be un-powered therefore using up sensor calibration life when operation of the OGS is not required.

\section{HYDROGEN SENSOR ORU LIFE EXTENSION}

The previous Hydrogen Sensor calibration life prior to life extension testing would have required that the OGS be shut down every 90 days for removal and replacement of the sensor (Reference 4). This 90 day life was established early in the development of the sensor based on historical testing results. Life extension testing was initiated due to the strong desire to extend the life 
and to conserve crew time and logistics. The life . extension potential looked positive because a qualification Hydrogen Sensor ORU had run for an extended period of time beyond the 90 day life and all three sensor dies stayed within calibration limits.

Two flight Hydrogen Sensors were tested for 200 days beyond their acceptance testing (Reference 8 ). The goal of the life extension test was to increase life from 90 to 180 days. The 200 day test duration was selected because it would allow a $10 \%$ margin over the 180 day goal.

The two Hydrogen Sensor ORUs were simultaneously tested for the 200 day duration. Each ORU has three Hydrogen Sensors, for a total of six sensors to be tested. Test conditions were the following; Inlet oxygen temperature of $70^{\circ} \mathrm{F}$ with a nominal dew point of $60^{\circ} \mathrm{F}$, interface temperature of $70^{\circ} \mathrm{F}$ with background Hydrogen of $100 \mathrm{~Pa}$. These conditions were selected to mimic nominal OGS conditions for the sensor.

During the 200 days of testing the six sensors were checked for accuracy at 30 day increments. This was completed by passing a known amount of Hydrogen from $\sim 300 \mathrm{~Pa}$ to $\sim 1575 \mathrm{~Pa}$ with two additional data points in between. The accuracy of the sensors was taken at two separate conditions. First, at $60^{\circ} \mathrm{F}$ dew point with oxygen temperature of $70^{\circ} \mathrm{F}$ and interface temperature of $90^{\circ} \mathrm{F}$. Secondly, at $85^{\circ} \mathrm{F}$ dew point with oxygen temperature of $100^{\circ} \mathrm{F}$ and interface temperature of $100^{\circ} \mathrm{F}$. The first condition was considered to be OGS sensor conditions of a new cell stack and the second to be OGS sensor conditions with a cell stack at end of life. Sensor pass/fail criteria required the sensor reading to be within $+/-180 \mathrm{~Pa}$ of the calibration limit.

The results were as follows in Table 1:

At the 30 and 60 day intervals all sensors were within $+/$ $70 \mathrm{~Pa}$.

At the 120 day interval all data all sensors were within $+/-115 \mathrm{~Pa}$.

At the 180 day interval all data all sensors were within $+/$ - $150 \mathrm{~Pa}$.

Table 1: Hydrogen Sensor ORU Specific Results

At the 200 day interval five of the six sensors were within $+/$ - $180 \mathrm{~Pa}$ calibration limit. One sensor exceeded the $180 \mathrm{~Pa}$ by $6 \mathrm{~Pa}$. Actual Hydrogen partial pressure was $1194 \mathrm{~Pa}$, the sensor indicated a partial pressure of 1008 $\mathrm{Pa}$. The test was repeated after two more days to verify readings results were similar with an outage of $5 \mathrm{~Pa}$. See results of this Hydrogen Sensor ORU (3 sensors) in Figure 12:

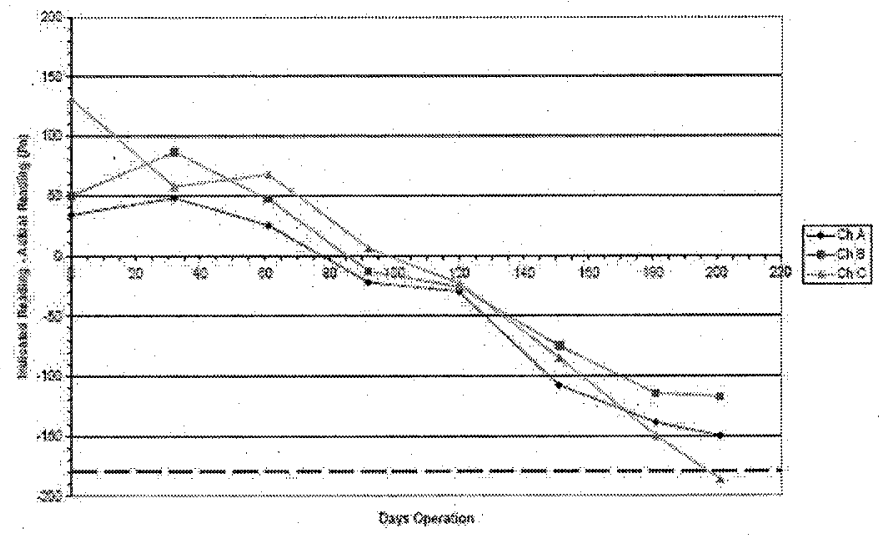

Figure 12: SN 1002 Calibration Check

Even though all six sensors were within tolerance after the 180 calibration check and one just outside tolerance limits at 200 days, it was decided to be conservative and extend the 90 day life of the Hydrogen sensor to 150 days.

Typical data for one sensor from the life extension test is shown in Figure 13:

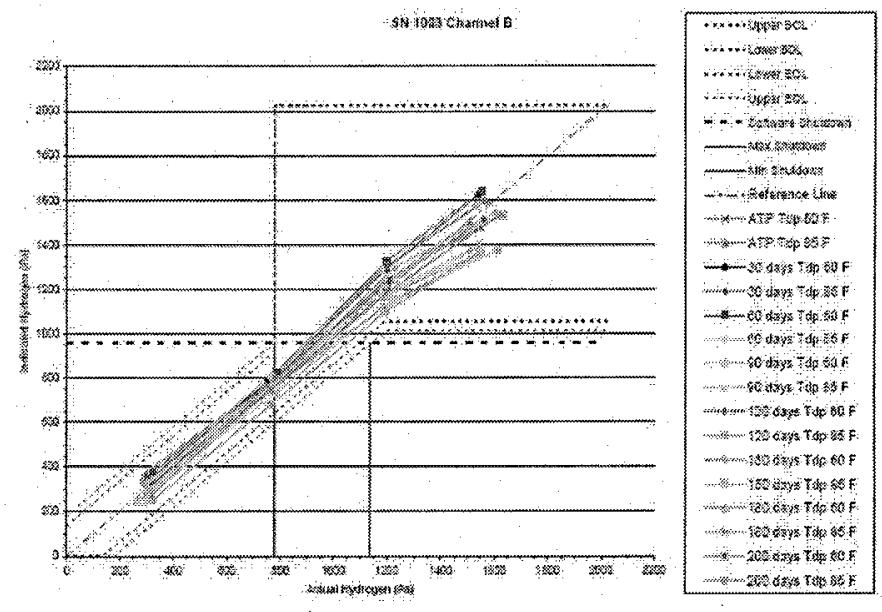

Figure 13: SN 1003 Channel B (single sensor)

\section{SUMMARY}

The ISS Oxygen Generation System was launched in July 2006 and has successfully undergone three periods of operation in the period July 2007 and March 2008.

Further evaluation of OGS performance, with periodic operation, will continue in anticipation of WRS activation in November 2008. With WRS support, longer runtime will be achievable. 
1. Bagdigian, R. M. and K. Prokhorov, "On-Orbit Checkout and Activation of the ISS Oxygen Generation System", SAE 2007-01-3182, $37^{\text {th }}$ International Conference on Environmental Systems, Chicago, IL, July 2007.

2. Bagdigian, R. M., D. Cloud, and J. Bedard, "Status of the Regenerative ECLSS Water Recovery and Oxygen Generation Systems," SAE "2006-01-2057, $36^{\text {th }}$ International Conference on Environmental Systems, Norfolk, VA, July 2006.

3. Bagdigian, R. M., and D. Cloud, "Status of the International Space Station Regenerative Water Recovery and Oxygen Generation Systems", SAE 2005-01-2779, $35^{\text {th }}$ International Conference on Environmental Systems, Rome, July 2005.

4. M'Sadoques, G. and Makel, D., "Flight Hydrogen Sensor for use in the ISS Oxygen Generation Assembly" SAE 2005-01-2870, $35^{\text {th }}$ International Conference on Environmental Systems, Rome, July 2005.

5. Carrasquillo, R.L., Cloud, D., and Kundrotas, R., "Status of the Node 3 Regenerative ECLSS Water Recovery and Oxygen Generation Systems," SAE 2004-01-2385, 34 International Conference on Environmental Systems, July 2004.

6. Carrasquillo, R.L., "'Status of the Node 3 Regenerative ECLSS Water Recovery and Oxygen Generation Systems", SAE 2003-01-2590; $33^{\text {rd }}$ International Conference on Environmental Systems; Vancouver, B.C., July 2003

7. Williams, D.E., Lewis, J., Carrasquillo, R.L., Reysa, R., and Gentry, G., "International Space Station Environmental Control and Life Support System Status: 2001-2002", SAE 2002-01-2494; $32^{\text {nd }}$ International Conference on Environmental Systems; San Antonio, Texas, July 2002.

8. Makel Engineering Inc. Report "Calibration Verification Testing SN 1002 and 1003200 day Report" MEI-FCT120SV826167-1 dated 11-12-07

\section{CONTACTS}

The primary author may be contacted at:

\section{Robert Erickson}

NASA Marshall Space Flight Center

Mailcode ES22

Huntsville, AL 35812

robert.j.erickson@nasa.gov 